\title{
Atrofia muscular esquelética. Modelos experimentais, manifestações teciduais e fisiopatologia
}

\author{
Rita Ferreira ${ }^{1,2}$ \\ Maria J. Neuparth ${ }^{1,2}$ \\ António Ascensão ${ }^{1}$ \\ José Magalhães ${ }^{1}$ \\ José Duarte ${ }^{1}$ \\ Francisco Amado
}

https://doi.org/10.5628/rpcd.04.03.94

\section{RESUMO}

A atrofia muscular esquelética tem-se constituído, nos últimos anos, como objecto de investigação, uma vez que se encontra associada a várias patologias, nomeadamente à insuficiência cardíaca, à sida, à sépsia, a algumas neoplasias, bem como, a alguns determinismos biológicos como o envelhecimento. No entanto, os mecanismos subjacentes às alterações morfológicas, bioquímicas e funcionais induzidas por esta entidade anatomopatológica permanecem, ainda, por esclarecer. Efectivamente, têm sido recentemente apresentadas algumas hipóteses, salientando-se as alterações no turnover proteico, no padrão de expressão das isoformas da miosina de cadeia pesada e na preponderância das vias metabólicas activadas. Adicionalmente, quer a diminuição do número de mionúcleos, quer a redução do domínio nuclear parecem ser fenómenos que acompanham o desenvolvimento da resposta atrófica. Neste sentido, vários estudos experimentais sugerem que a apoptose parece ter uma função importante na regulação destes acontecimentos. Dada a relevância e implicação clínica da atrofia muscular na capacidade funcional e, consequentemente, na qualidade de vida do ser humano, torna-se fundamental compreender de forma detalhada este processo. Como se desenvolve, de que forma se manifesta e quais os pontos chave da fisiopatologia da atrofia, são algumas das questões focadas neste trabalho.

Palavras-chave: atrofia, apoptose, necrose, proteólise, proteínas de choque térmico.

\author{
${ }^{1}$ Faculdade de Ciências do Desporto e de Educação Física \\ Universidade do Porto \\ Portugal \\ ${ }^{2}$ Departamento de Química \\ Universidade de Aveiro \\ Portugal
}

\author{
ABSTRACT \\ Skeletal muscle atrophy. \\ Physiopathology and experimental models
}

Skeletal muscle atrophy is closely associated to many clinical disorders such as cardiac failure, AIDS, sepsis, cancer and other biological phenomenon like ageing, that compromise human health and life style. For this reason, atrophy has been the focus of several clinical and basic research studies in the last decades. However, the mechanisms behind atrophy-induced morphologic, biochemical and functional alterations are still currently not well understood. Indeed, several possibilities regarding its physiopathology have been envisioned including unbalanced protein turnover, changes in the myosin heavy chain expression pattern and in the metabolic shift towards glycolitic pathway. In addition, the reduction of both myonuclear number and myonuclear domain size also suggest that apoptosis may be imperative in the regulation of these events. Given the clinical importance of this topic concerning the improved quality of life and functional ability, this issue needs to be addressed in greater detail. How does atrophy develop, what are the main signs and which are the new known key points of its physiopathology? This treatise highlights some of these questions and tries to contribute to a better understanding of the fundamental biochemical mechanisms behind skeletal muscle atrophy.

Key Words: atrophy, apoptosis, necrosis, proteolysis, heat shock proteins. 


\section{INTRODUÇÃO}

O processo de atrofia muscular esquelética constitui uma resposta do tecido muscular em situações de tensão e/ou de carga mecânica reduzida, na tentativa de manter um funcionamento eficiente e ajustado às novas exigências funcionais ${ }^{(28)}$. Desta forma, este processo pode ser visto como uma expressão da deterioração muscular em resposta a alterações funcionais ou patológicas ${ }^{(59)}$. A atrofia muscular esquelética constitui um processo altamente ordenado e regulado ${ }^{(19)}$ com inúmeras alterações metabólicas, bioquímicas e estruturais que se repercutem na funcionalidade dos músculos afectados ${ }^{(7,8)}$. A estrutura e a funcionalidade muscular esquelética são condicionadas pela actividade proprioceptiva, pela enervação motora, pela carga mecânica, pela realização de ciclos de estiramento/encurtamento e pela mobilidade das articulações ${ }^{(7)}$. Quando algum destes factores é comprometido, a atrofia desenvolve-se de forma imediata e drástica ${ }^{(7)}$, deteriorando a qualidade de vida humana dado que esta é condicionada pelas actividades que o indivíduo é capaz de realizar. Desta forma, o conhecimento detalhado da fisiopatologia da atrofia muscular poderá ter importantes repercussões no desenvolvimento de medidas preventivas para a sua manifestação assim como na definição de protocolos de reabilitação ${ }^{(21)}$.

\section{MODELOS EXPERIMENTAIS}

No sentido de estudar os mecanismos subjacentes ao processo de atrofia muscular esquelética, têm vindo a ser desenvolvidos vários modelos animais capazes de a induzir experimentalmente ${ }^{(18,19,51)}$, salientando-se os modelos de suspensão do membro traseiro, de voo espacial, de isolamento da espinal medula e o de imobilização.

\section{Suspensão do membro traseiro}

Este modelo de indução de atrofia muscular esquelética foi inicialmente desenvolvido em 1979 com a finalidade de simular um ambiente de ausência de peso, nomeadamente para mimetizar o voo espacial. Constitui o modelo experimental de eleição, aceite pela comunidade científica, para simular o voo espacial, prevendo-se um aumento da sua utilização durante a era da estação espacial ${ }^{(61,91)}$. Este modelo de hipocinesia e de hipodinâmica ${ }^{(91)}$, muito utilizado no estudo do efeito da ausência da carga, também se mostrou útil na investigação da resposta fisiológica de ratos e ratinhos em processos de recuperação associados à reposição da carga ${ }^{(61)}$. As adaptações fisiológicas que ocorrem neste modelo são semelhantes às observadas em outros modelos experimentais de uso muscular reduzido, como a desnervação e a imobilização, o que lhe confere uma utilidade dupla: se, por um lado, permite estudar sistemas fisiológicos sob condições de microgravidade simulada, por outro, as alterações são comparáveis a outros modelos com actividade muscular reduzida ${ }^{(61)}$.

\section{Voo espacial}

O voo espacial constitui, à semelhança da suspensão do membro traseiro, um modelo de activação eléctrica reduzida dos músculos posturais ${ }^{(86)}$. O número de elementos neurais da função neuromotora são rápida e profundamente afectados pelo voo espacial, sendo que algumas destas adaptações persistem durante dias ou mesmo semanas após o mesmo ${ }^{(29)}$. Segundo estes autores, o componente neural parece, assim, possuir um papel decisivo para o detrimento da performance associado ao voo espacial ${ }^{(29)}$.

Os programas espaciais demonstram que a atrofia muscular em ratos ocorre rapidamente, verificandose reduções de massa muscular, superiores a $37 \%$ numa semana ${ }^{(31)}$, observáveis em músculos extensores mas não em outros músculos associados ao movimento ${ }^{(61)}$.

Neste modelo, à semelhança do anterior, as forças da reacção à gravidade são eliminadas, permitindo simultaneamente que os músculos permaneçam funcionalmente activos ${ }^{(9,42)}$.

\section{Isolamento da espinal medula}

$\mathrm{O}$ isolamento da espinal medula é um modelo indutor de inactividade que permite estudar experimentalmente o impacto relativo de um determinado estímulo neural na resposta muscular ${ }^{(28)}$. A espinal medula é cortada a um nível estratégico, de modo a eliminar o controlo superior sobre os centros de controlo espinal neuromotor abaixo da lesão ${ }^{(42)}$. A actividade eléctrica dos neurónios motores pode ser activada por estímulos sensoriais, mas a produção de força pelos músculos é dramaticamente reduzida ${ }^{(9)}$. Algumas das propriedades contrácteis do músculo 
reflectem tendencialmente estas adaptações; a tensão tetânica máxima é significativamente reduzida, enquanto que a velocidade de encurtamento máximo é significativamente elevada. Por sua vez, as propriedades de fadiga muscular são só moderadamente afectadas ou, em alguns casos, nem o chegam a ser ${ }^{(28)}$. A desnervação constitui um modelo semelhante ao do isolamento da espinal medula, onde os sinais eléctricos que chegam às fibras musculares são atenuados e/ou silenciados ${ }^{(28,42)}$. As conexões musculares nervosas são seccionadas bem como a actividade de suporte postural e qualquer influência trófica do neurónio motor ou nervo que actua no músculo. Desta forma, a contracção e a utilização muscular diminuem e ocorre atrofia da fibra muscular ${ }^{(42)}$.

\section{Imobilização}

Um outro modelo considerado adequado para estudar os mecanismos responsáveis pela atrofia muscular em humanos é a imobilização decorrente de distintos contextos clínicos, uma vez que neste processo espera-se que os factores subjacentes à etiologia sejam expressos de forma distinta durante as primeiras fases ${ }^{(81)}$. A atrofia muscular associada a este modelo surge rapidamente, é reversível e afecta de forma idêntica os diferentes músculos (para refs. ver ${ }^{51)}$.

Neste modelo, os músculos alvo são imobilizados numa posição fixa por inactivação/imobilização das articulações. Deste modo, o músculo é mantido numa posição neutra, encurtada ou alongada ${ }^{(42)}$. Todos estes modelos têm em comum o facto de minimizarem a quantidade de actividade induzida pela carga mecânica desempenhada pelo músculo ${ }^{(42)}$.

\section{MANIFESTAÇõES CLÍNICAS}

A atrofia muscular esquelética resulta na perda de volume muscular e na redução drástica da capacidade deste em gerar força ${ }^{(17,25,31,38,46,48,51,59)}$. A perda de força muscular constitui uma característica funcional

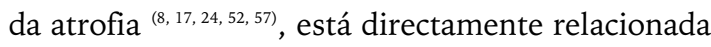
com a diminuição da área transversal das fibras que compõem o músculo ${ }^{(8,28,48)}$ e com a perda de proteínas contrácteis ${ }^{(24,25,58)}$. A perda de massa pelos músculos atrofiados ocorre de uma forma temporal semelhante à perda de força ${ }^{(8,19,42,57)}$. As maiores diminuições são observadas na fase inicial de imobilização, registando-se posteriormente ao longo do tempo um declínio mais ligeiro ${ }^{(8)}$. Os músculos extensores, como o soleus, o vastus intermedius e o plantaris, são os que evidenciam perdas mais acentuadas de massa muscular ${ }^{(13)}$.

Associada à atrofia ocorrem alterações das propriedades contrácteis que são mais evidentes nos músculos anti-gravitacionais como, por exemplo, no músculo soleus ${ }^{(13)}$ devido à sua composição homogénea em fibras lentas ${ }^{(8,58)}$.

Em vários estudos animais foi observado um aumento da velocidade de encurtamento das fibras lentas sob ausência de carga ${ }^{(19,21,25)}$. Experiências com humanos e com ratos demonstram, ainda, de uma forma consistente, que a velocidade máxima de encurtamento aumenta em consequência do voo

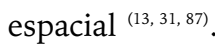

O aumento da velocidade de contracção máxima, verificado numa situação de atrofia, parece constituir um mecanismo para manutenção de um output máximo de força por unidade de tempo, de modo a permitir um nível adequado de capacidade locomotora no caso de restauração da mobilidade ${ }^{(87)}$.

$\mathrm{O}$ aumento da fatigabilidade constitui outra das con-

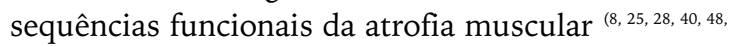
${ }^{87,95)}$. Este aumento é muitas vezes atribuído a uma diminuição do potencial metabólico das fibras individuais ${ }^{(23,25,28)}$, mas o efeito mais dramático na fatigabilidade pode ser explicado pela necessidade em recrutar um maior número de unidades motoras ou pela maior frequência de excitação requerida num músculo atrofiado para desempenhar um dado tipo de tarefa motora ${ }^{(28,87)}$.

Talmadge et al. ${ }^{(87)}$ sugerem, ainda, que a expressão de isoformas MHC mais rápidas (IIB e IIX), observada numa situação de atrofia, requer uma maior utilização de ATP por unidade de força gerada, aumentando, assim, a susceptibilidade à fadiga.

A atrofia preferencial das fibras lentas também parece contribuir para um aumento da fatigabilidade dado que as fibras tipo I têm uma maior capacidade em manter o balanço energético e consequentemente a força relativamente às fibras tipo II ${ }^{(15)}$.

Também a actividade eléctrica dos músculos atrofiados diminui drasticamente ${ }^{(8,95)}$, afectando as propriedades bioquímicas e funcionais do músculo ${ }^{(22,91)}$. A imobilização coloca o músculo num estado passivo e reduz a sua actividade electromiográfica (EMG) ${ }^{\left({ }^{(4)}\right)}$. 
Por exemplo, a actividade EMG no soleus sofre uma redução de cerca de $10 \%$ do normal durante a ausência de peso e só retorna aos valores normais por volta do $10^{\circ}$ dia de suspensão do membro traseiro ${ }^{(22)}$. Os registos EMG crónicos de bicepes brachi imobilizados em humanos são $10 \%$ menores do que nos mesmos músculos não imobilizados ${ }^{(46)}$.

Os músculos atrofiados estão ainda sujeitos a um maior risco de lesão face a qualquer situação de emergência que requeira força muscular ${ }^{(11)}$. Numa situação de microgravidade ocorre uma perda contínua de proteínas musculares e de cálcio dos ossos, essencialmente dos que desempenham uma função anti-gravítica ${ }^{(31,82,95)}$. Efectivamente, nos astronautas tem sido registada uma elevada incidência de lesões ${ }^{(31)}$. Castro et al. ${ }^{(15)}$ observaram um aumento da vulnerabilidade à lesão muscular induzida pelo exercício, em humanos e ratinhos, após um curto período de ausência de peso. O aumento simultâneo de rarefacção óssea observada numa situação de atrofia muscular ${ }^{(17,32)}$ dificulta e prolonga consideravelmente os períodos de reabilitação ${ }^{(17,95)}$.

A concentração plasmática de algumas proteínas miofibrilares é, normalmente, utilizada para estimar a ocorrência de lesão do músculo esquelético e a sua magnitude ${ }^{(79)}$, salientando-se a creatina kinase (CK), a aspartato aminotransferase, a lactato desidrogenase, a mioglobina e a troponina ${ }^{(48)}$. O aumento dos seus níveis plasmáticos constitui uma indicação de que as células musculares atingidas perderam a capacidade de regular a permeabilidade destas proteínas ${ }^{(49)}$. Dos referidos, a CK é um dos marcadores mais usados na clínica para diagnóstico de lesão muscular ${ }^{(49)}$. Numa situação de atrofia, como por exemplo na imobilização, a CK é sobre-expressa, o que a torna um bom marcador da adaptação do músculo esquelético ao desuso ${ }^{(19)}$, sendo por isso o mais frequentemente utilizado ${ }^{(79)}$. No entanto, a troponina I (TnI) tem sido referida como um marcador de lesão mais específico na detecção de lesão do músculo esquelético (sTnI) e cardíaco (cTnI) ${ }^{(48)}$. Esta proteína tem sido mais utilizada na monitorização de lesões ao nível do músculo cardíaco, apesar de existirem estudos que validam a sua aplicação ao nível do músculo esquelético e a consideram o marcador de lesão mais adequado dada a sua especificidade ${ }^{(79)}$.

\section{ETIOLOGIAS E EVOLUÇÃO TEMPORAL}

A redução da actividade neuromuscular e/ou a ausência de carga devida à desnervação, à suspensão de um membro, à ausência de gravidade e a uma deficiência em nutrientes - como a vitamina E e o selénio - induzem a atrofia muscular ${ }^{(13)}$.

O envelhecimento também é acompanhado por um declínio funcional acelerado e pela restrição do potencial adaptativo ${ }^{(67,69)}$. Com a idade observa-se uma tendência para uma menor actividade física, que parece constituir um fenómeno biológico universal que ocorre nas diferentes espécies animais. A diminuição da secreção das hormonas anabólicas circulantes, bem como a reduzida síntese proteica muscular, também condicionam a performance muscular em indivíduos idosos ${ }^{(94)}$. A concentração de IGF-I (factor de crescimento tipo insulínico), produzida pelo músculo, parece também desempenhar um papel importante a este nível ${ }^{(43)}$

Uma série de desordens em humanos pode induzir uma atrofia muscular progressiva que, em última análise, pode culminar na morte por insuficiência respiratória ${ }^{(75)}$. A insuficiência cardíaca, por exemplo, caracteriza-se pela diminuição da tolerância ao exercício que se pensa estar relacionada com uma miopatia específica do músculo esquelético ${ }^{(6,89)}$. A atrofia muscular é observada também em outros tipos de doenças sistémicas, como é o caso de certos tipos de cancro, da sepsis, da insuficiência renal e da SIDA ${ }^{(89)}$. A elevada concentração endógena de esteróides que se observa em algumas patologias, como, por exemplo, no Síndrome de Cushing ou em tumores adrenais, bem como na administração experimental de drogas esteróides, também pode levar à perda de massa muscular ${ }^{(20)}$.

A resposta atrófica às diversas etiologias parece ser músculo - específica, não só em humanos, como também em mamíferos inferiores ${ }^{(15)}$.

Os músculos fenotipicamente lentos, compostos predominantemente por fibras tipo I, adaptam-se mais eficazmente do que os músculos rápidos (fibras tipo II) ${ }^{(8,87)}$, assim como os músculos com uma função predominantemente extensora apresentam um maior grau de adaptação a estímulos atróficos do que os flexores ${ }^{(87)}$. Os músculos esqueléticos anti-gravidade, como o soleus, apresentam um maior grau de atrofia (das suas fibras musculares lentas) numa situação de ausência de gravidade ${ }^{(13)}$. 
Talmagde et al. ${ }^{\left({ }^{87}\right)}$ observaram que as adaptações nas propriedades mecânicas do gastrocnemius médio, um extensor rápido, são menos pronunciadas do que nas do soleus de gatos submetidos a isolamento da espinal medula. Mais ainda, as propriedades mecânicas do tibialis anterior, um flexor rápido, são minimamente afectadas por 6-8 meses de isolamento da espinal medula ${ }^{\left({ }^{(7)}\right)}$.

Edgerton et al. ${ }^{(28)}$ sugeriram, também, que a resposta atrófica a uma ausência prolongada de estímulo eléctrico parece ser mais específica do tipo de músculo do que do tipo de fibra muscular. Para estes autores, o grau de atrofia da fibra é proporcional à percentagem de fibras lentas num dado músculo.

A manifestação da atrofia muscular esquelética pode ser bastante rápida. Por exemplo, o músculo soleus de ratos sofre atrofia de $25 \%$, após 4 dias, e de aproximadamente $36 \%$, após 7 dias de voo espacial, estabilizando ao fim de 2 semanas de ausência de gravidade ${ }^{(28)}$.

A atrofia induzida pela imobilização, avaliada pela perda de força e de massa muscular, segue um padrão típico: as maiores alterações ocorrem durante os primeiros dias de imobilização, enquanto que com o prolongamento do desuso a velocidade de perda diminui ${ }^{(8)}$. Ohira et al. ${ }^{(64)}$ registaram uma evolução bastante rápida do processo atrófico nas fases iniciais, isto é, nos primeiros 7-10 dias de suspensão do membro traseiro de rato, aos quais se segue um desenvolvimento moderado.

A longo prazo, e dependendo do estímulo indutor da atrofia, a evolução do processo atrófico pode ser dividida em 3 fases ${ }^{(57)}$. Na desnervação, por exemplo, observa-se, numa primeira fase (nos primeiros 2 a 3 meses) uma profunda atrofia do músculo, avaliada pela diminuição da massa e da força máxima, durante a qual o músculo é capaz de restauração reenervado. Na fase 2 (nos 2 a 7 meses após desnervação) a capacidade restaurativa do músculo diminui acentuadamente, observando-se uma redução do número de mionúcleos e de células satélite. Na fase 3 (após 7 meses de desnervação) todos os parâmetros relacionados com a atrofia (ie, redução da massa, da força contráctil, do número de células satélite, da densidade capilar e aumento da quantidade de tecido conjuntivo intersticial) estabilizam num nível basal.

\section{ALTERAÇÕES HISTOLÓGICAS}

A atrofia muscular caracteriza-se histologicamente por uma diminuição da densidade de volume miofibrilar relativamente aos volumes mitocondrial e do retículo sarcoplasmático ${ }^{(13)}$.

As fibras lentas oxidativas, mais susceptíveis à atrofia, apresentam fibrilas desintegradas, com as linhas$\mathrm{Z}$ estendidas ${ }^{(8,48)}$ e lesão mitocondrial ${ }^{(8,13)}$. As mitocôndrias tornam-se menores, de forma mais globular e com poucas cristas ${ }^{(57)}$. À medida que a área transversal da fibra diminui, os núcleos encontram-se mais frequentemente no centro das fibras ${ }^{(48,57)}$ e a rodear alguns destes observam-se halos de citoplasma sem miofibrilas ${ }^{(48,57)}$. A condensação e a fragmentação da cromatina nuclear são características das fibras atróficas ${ }^{(8,57,76)}$. O retículo sarcoplasmático torna-se mais irregular e perde a sua íntima relação com os túbulos $\mathrm{T}$ ao nível das junções anisotrópicas - isotrópicas ${ }^{\left({ }^{57}\right)}$. O número de sarcómeros funcionais em paralelo, aparentemente, tem tendência a diminuir ${ }^{(13,48)}$.

A redução progressiva da razão capilar/fibra muscular, característica do processo atrófico, pode induzir ou contribuir, pelo menos em parte, para a degeneração das fibras musculares existentes ${ }^{(57)}$. Kano et al. (47) constataram que a atrofia, decorrente da suspensão do membro traseiro em ratos, é acompanhada por uma diminuição do diâmetro luminal capilar, bem como por uma redução do número absoluto de capilares. Também Edgerton et al. ${ }^{(29)}$ registaram uma diminuição significativa do número de capilares nos diferentes tipos de fibras (I, IIA e IIB) após 11 dias de voo espacial.

Caiozzo et al. ${ }^{(13)}$ observaram ainda que o voo espacial induz no músculo soleus um aumento do tecido conjuntivo ou fluido intersticial. Também a desnervação de músculo de rato e ratinho adulto induz inicialmente a proliferação de tecido conjuntivo e de células satélite ${ }^{(74)}$. A morfologia das células satélite em músculos desnervados sugere que muitas destas abandonam o seu estado quiescente e tornam-se activadas, estando potencialmente disponíveis para a restauração das fibras musculares atróficas existentes ou para a regeneração de novas fibras musculares ${ }^{(57)}$. Apesar desta aparente estimulação inicial, ${ }^{(22)}$ registaram uma diminuição do número e da actividade proliferativa das células satélite após 3 dias de 
suspensão do membro traseiro nos músculos soleus e extensor digitorium longus (EDL) de rato. A diminuição do teor em células satélite e do seu potencial proliferativo, parece estar subjacente à diminuição da capacidade adaptativa e regenerativa que se observa, por exemplo, no envelhecimento muscular ${ }^{(69)}$. O aumento de áreas densas de colagénio, a rodear as fibras musculares e os fascículos dos músculos atróficos, sugere que as fibras de colagénio podem actuar como uma barreira física ao ingrowth dos nervos, impedindo a enervação de fibras musculares que se apresentam histologicamente pequenas ${ }^{(57)}$.

Um aumento de gordura e de fagócitos no espaço entre as fibras também tem sido associada à atrofia ${ }^{(8,48)}$. A infiltração de fagócitos tem sido encontrada raramente nas primeiras fases de atrofia ${ }^{(51)}$, mas tem sido registada pouco tempo após a reposição da carga ${ }^{(35,62)}$. Os macrófagos segregam substâncias, tais como o factor de crescimento derivado das plaquetas, o factor de crescimento tipo-fibroblástico e o factor de crescimento tipo-insulínico, que estimulam a actividade mitótica das células satélite ${ }^{(62)}$. Dado o seu papel no processo reparador da lesão, decorrente da reposição de carga, os macrófagos funcionam como fagócitos no músculo ${ }^{(80)}$.

\section{ALTERAÇÕES BIOQUÍMICAS E METABÓLICAS}

A molécula de miosina de cadeia pesada (MHC) é a principal proteína estrutural e reguladora que serve de motor molecular no controlo das propriedades contrácteis intrínsecas da fibra muscular ${ }^{(1,86)}$. O músculo esquelético é essencialmente caracterizado pelas isoformas MHC específicas. Conhecem-se quatro isoformas MHC expressas em níveis elevados nos músculos de roedores adultos: MHC I (ou $\beta$-cardíaca), MHC IIa, MHC IIx (ou MHC IId) e MHC IIb. A expressão singular de cada uma destas isoformas na fibra resulta no aparecimento de quatro tipos de fibras diferentes ${ }^{(86)}$. Assim, as fibras tipo I são compostas por MHC I ${ }^{(13,86)}$, típica das fibras resistentes à fadiga, e são caracterizadas por um baixo consumo de ATP e por uma reduzida velocidade de encurtamento ${ }^{(13)}$. As fibras tipo IIA e IIB são constituídas por MHC IIa e IIb, respectivamente ${ }^{(13,86,93)}$. Estas isoformas rápidas são características das fibras que apresentam um elevado consumo de ATP, uma maior velocidade de encurtamento e são mais fatigáveis ${ }^{(13,}$
${ }^{93)}$. As fibras tipo IIX são constituídas por isoformas MHC IIx. Nos humanos e nos gatos, a isoforma MHC IIb não é expressa, pelo que não se observam fibras do tipo IIB ${ }^{(86)}$. Em adição às fibras que contêm apenas uma das isoformas MHC, também se conhecem fibras "híbridas" que co-expressam duas ou mais isoformas MHC ${ }^{(6,86)}$. O conhecimento da composição da fibra muscular em isoformas MHC é importante, dado que esta condiciona certas propriedades contrácteis, como a velocidade máxima de encurtamento, e propriedades intrínsecas geradoras de força ${ }^{(87)}$.

No estado adulto, a expressão das MHC do músculo esquelético é altamente plástica e o padrão fenotípico pode ser influenciado por vários factores exógenos, como alterações na exigência funcional (diminuição ou exagero do uso) e alterações nos níveis hormonais ${ }^{(13,19,41)}$.

$\mathrm{Na}$ atrofia muscular estão descritas alterações na expressão das isoformas MHC, observáveis em situações distintas tais como na suspensão do membro traseiro em ratos, durante o voo espacial em ratos, humanos e macacos rhesus ${ }^{(13,16,19,88)}$ e ainda na desnervação e na tenotomia em ratos ${ }^{(84)}$.

Talmadge et al ${ }^{(88)}$ observaram que tanto a suspensão do membro traseiro como o voo espacial induzem, no músculo soleus de rato Wistar, um aumento da proporção de fibras contendo MHC tipo II em detrimento das tipo I (Figura 1A e 1B). Posteriormente, Cros et al. ${ }^{(19)}$, para além de confirmarem estas alterações no teor das isoformas MHC no músculo soleus, sugeriram ainda que a resposta deste músculo à ausência de carga é um processo contínuo, uma vez que as curvas de variação da percentagem de isoformas MHC não estabilizam mesmo após 4 semanas de suspensão do membro traseiro. Estas alterações parecem ocorrer por transições sequenciais na expressão das isoformas MHC (I $\rightarrow$ IIa $\rightarrow$ IId(x) $\rightarrow$ IIb) ${ }^{(83,87)}$ e parecem ser afectadas pela idade, sendo mais evidentes em ratos jovens ${ }^{(72)}$.

A indução da expressão da MHC tipo IIx, que não é normalmente expressa no músculo soleus de rato, bem como um aumento da concentração relativa de MHC tipo IIa, após 6 dias de voo espacial ou após 14-31 dias de suspensão do membro traseiro (Figura 1A e 1B) foram alterações observadas por Talmadge et al. ${ }^{(88)}$. O mesmo foi constatado por Allen et al. ${ }^{(5)} \mathrm{e}$ 
Stevens et al. ${ }^{(84)}$ ao estudarem as fibras do músculo soleus individualmente. Os primeiros observaram, em geis de electroforese de fibras individuais, que as MHC tipo IIx eram expressas em, aproximadamente, $8 \%$ das fibras de rato controlo que também expressavam simultaneamente MHC tipo IIa. Esta baixa quantidade de MHC tipo IIx expressa em fibras controlo é dificilmente detectada quando se utilizam homogeneizados de músculo inteiro. Também Ohira et al. ${ }^{\left({ }^{64)}\right.}$ observaram, no músculo esquelético humano submetido a ausência de carga, um aumento do número de fibras musculares que expressam isoformas MHC rápidas. As fibras tipo I são as mais afectadas por alterações crónicas ao nível da actividade neuromuscular, talvez porque estas fibras são normalmente as mais activas (Figura 2). No entanto, é de considerar que no músculo soleus, os outros tipos de fibras representam uma fracção muito pequena da população total de fibras, pelo que a contribuição das adaptações destas fibras minoritárias, ao nível do músculo como um todo, parecem ser fisiologicamente insignificantes ${ }^{(64)}$.

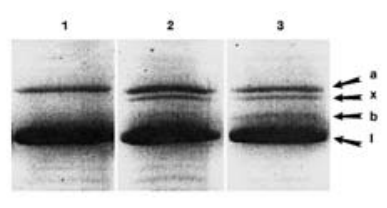

Figura 1A: SDS-PAGE evidenciando as diferentes isoformas de MHC em músculo soleus de ratos controlo (linha 1), com suspensão do membro traseiro (linha 2) e voo espacial (linha 3). [Adaptado de 88)

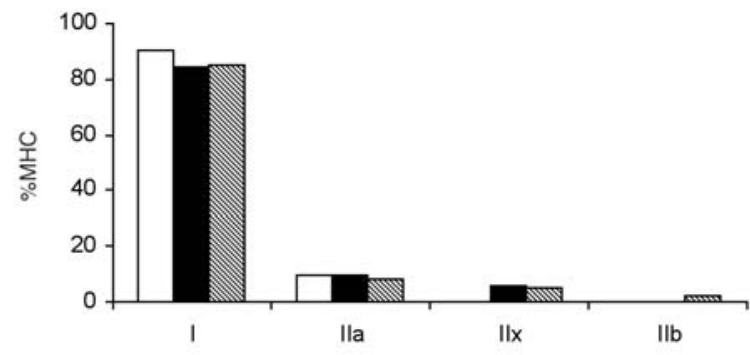

$\square$ controlo $\mathbf{m}$ suspensão do membro traseiro $\mathbb{Q}$ voo espacial

Figura 1B: Composição percentual das isoformas MHC do músculo soleus de rato controlo, com suspensão do membro traseiro e submetidos a voo espacial (Adaptado de 88).

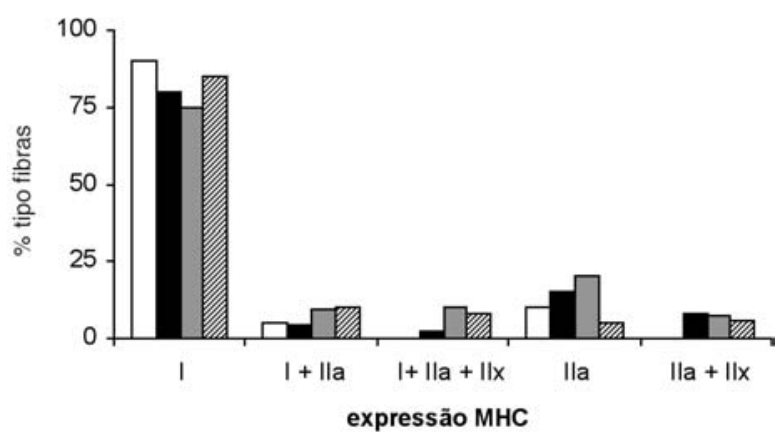

Figura 2: Distribuição dos tipos de fibras baseadas na expressão MHC no músculo soleus antes, após 2 e 4 meses de acamamento e após um mês de recuperação (Adaptado de 64).

Nas regiões vermelhas de músculos mistos, como o gastrocnemius, também se verifica um aumento da proporção de fibras que contêm MHC tipo II ${ }^{(88)}$. No músculo vastus intermedius observaram-se alterações no tipo de fibras, qualitativamente semelhantes às do soleus, mas menores em magnitude. Nos músculos plantaris e tibialis anterior não se registaram as alterações na composição das fibras musculares esperadas, atendendo a que a composição das fibras destes músculos é basicamente constituída por fibras musculares rápidas ${ }^{(13)}$.

A forma como é regulada esta alteração das isoformas MHC é uma questão que tem sido bastante abordada nos estudos de atrofia muscular mas para a qual ainda não se conhecem certezas absolutas. Paralelamente à atrofia muscular observada, por exemplo, durante a suspensão do membro traseiro, ocorre alteração da expressão genética ${ }^{(83)}$. Numa situação de ausência de carga, o teor proteico e os níveis de mRNA das isoformas que estão sobrereguladas são condicionados pela atrofia do músculo. Por exemplo, numa situação de atrofia acentuada observa-se uma diminuição dos níveis de MHC IIa numa altura em que os níveis de mRNA continuam a aumentar, o que poderá ser explicado pela regulação pós-transcripcional ${ }^{(46,83)}$.

Anteriormente, Caiozzo et al. ${ }^{(13)}$ tinham observado que a quantidade de RNA total não é afectada pelos 14 dias de microgravidade a que os ratos foram submetidos. Porque o rRNA constitui a maior parte do 
RNA total, esta observação sugere que um dos principais componentes da maquinaria requerida para a síntese proteica, o rRNA, não é dramaticamente afectado por tal exposição à microgravidade. Assim, a diminuição substancial no teor da isoforma lenta MHC tipo I (mg/músculo) observada no músculo soleus, sem uma concomitante diminuição no teor de mRNA da MHC tipo I, sugere um aumento marcante da degradação desta isoforma de MHC.

Contrariamente, o aumento simultâneo das proteínas MHC tipo IIx e do teor de mRNA desta isoforma, tanto no músculo soleus como no vastus intermedius, sugere que os mecanismos celulares que envolvem acontecimentos pré-tanslacionais terão um papel chave no que se refere ao aumento da expressão desta isoforma de MHC nestes músculos ${ }^{(13)}$. As modificações na expressão das MHC são acompanhadas por um aumento na razão das actividades das enzimas glicolíticas/oxidativas, não só pela redução da capacidade oxidativa do músculo esquelético, mas também pelo aumento acentuado do metabolismo glicolítico ${ }^{(19)}$. As enzimas metabólicas como a creatina kinase muscular ou a gliceraldeído-3-fosfato desidrogenase, são altamente expressas no músculo soleus imobilizado, dando indicação do elevado potencial glicolítico e da baixa resistência à fadiga que este músculo adquiriu ${ }^{(19,25,29,91)}$. Considerando que no músculo esquelético, em resposta a alterações de sobrecarga, as adaptações metabólicas precedem as adaptações estruturais ${ }^{\left({ }^{19}\right)}$, o aumento destas enzimas glicolíticas no processo atrófico pode ser visto como um bom marcador do desuso muscular. Gamrin et al. ${ }^{(38)}$ observaram que a oxidação do piruvato e a actividade de marcadores enzimáticos do ciclo do ácido tricarboxílico (TCA) não são afectadas pela ausência de gravidade, o que sugere que a reduzida capacidade em oxidar gorduras apresentada pelos músculos atróficos não é devida a uma diminuição do fluxo de substratos do ciclo TCA. Nos ratos, e talvez nos humanos, os modelos de ausência de peso provocam um aumento do teor de glicogénio no músculo em repouso cuja deplecção, bem como a produção de lactato, é acelerada durante a actividade. Este aumento da dependência do glicogénio está associada a uma capacidade reduzida em oxidar ácidos gordos livres ${ }^{225}$ ${ }^{31)}$ possivelmente causada pelo efeito inibitório do substrato de uma enzima limitante da velocidade da oxidação dos ácidos gordos ${ }^{(31)}$.
Os dados metabólicos obtidos de músculos de ratos expostos a voo espacial mostram que a integridade metabólica de músculos lentos, como o soleus, é mantida razoavelmente bem até $7-12,5$ dias, mesmo quando a atrofia é severa. No entanto, observam-se alterações de proteínas enzimáticas mitocondriais em músculos predominantemente rápidos após 7-14 dias de voo espacial. Tem sido sugerido que algumas destas modificações enzimáticas estão relacionadas com uma alteração da sensibilidade à insulina, podendo resultar de uma maior dependência do metabolismo anaeróbio de hidratos de carbono comparativamente ao normal ${ }^{(29,38)}$. O voo espacial resulta num aumento da actividade média da ATPase miofibrilar das fibras tipo II e num aumento da actividade da $\alpha$-glicerofosfato desidrogenase (GPD) em cerca de $80 \%$ em fibras tipo I ${ }^{(29)}$. No músculo gastrocnemius, que é solicitado para manter a postura e para realizar exercício de baixa e de elevada intensidade, é expressa uma grande quantidade de enzimas, quer para a fosforilação oxidativa (citocromo C oxidase I e III, citocromo b e subunidade 6 da ATPase) quer para a glicólise (GAPDH, fosfoglicerato mutase e aldolase A). A creatina kinase, que providencia uma fonte de energia rapidamente disponível, também é muito expressa neste músculo ${ }^{(81)}$.

Uma adaptação típica à diminuição do uso muscular provocada por desnervação, imobilização e suspensão do membro traseiro, é a redução dos níveis de proteínas mitocondriais, com consequente perda da funcionalidade da mitocôndria ${ }^{(18,81)}$. No entanto, a diminuição do uso muscular provocada por microgravidade parece produzir uma adaptação das proteínas mitocondriais do músculo esquelético inconsistente e pouco compreendida ${ }^{(18)}$. Por exemplo, os níveis de 3-hidroxiacil CoA desidrogenase diminuem no músculo soleus após 7 dias de voo espacial mas não sofrem alterações nos músculos vastus lateralis e vastus intermedius após 9 dias numa situação de microgravidade. Estas diferenças na regulação da expressão das proteínas mitocondriais parecem, pois, ser específicas do tecido. St-Amand et al. ${ }^{(81)}$ verificaram uma diminuição da expressão genética de enzimas envolvidas na produção de ATP tais como as subunidades $\beta, \delta, \gamma$ da ATP sintase e da subunidade VIII-h da citocromo C oxidase, entre outras. Dada a diminuição do fornecimento de energia, a glicólise pode ser promovida pela diminuição 
da actividade da fosfatase 1 que inactiva a fosforilase, enzima responsável pela degradação do glicogénio a glucose ${ }^{(81)}$.

No processo atrófico o volume celular diminui rapidamente e a estrutura celular altera-se drasticamente, pelo que é de esperar uma alteração do balanço e da distribuição dos iões metálicos ${ }^{(51)}$. Efectivamente, a composição elementar do músculo também tem sido estudada por alguns investigadores que constataram, por exemplo, um aumento acentuado da concentração de cloro e algum aumento da concentração de sódio no quadricipes de humanos após cirurgia e imobilização. Estas alterações parecem dever-se a um aumento da permeabilidade da membrana a estes iões que poderão participar na indução da ruptura da fibra ${ }^{(8)}$.

\section{FISIOPATOLOGIA}

\section{Alterações anabólicas/catabólicas}

Em termos gerais, a manutenção da capacidade funcional e da massa muscular é controlada por um balanço entre as vias de síntese e de degradação proteica ${ }^{(10,77)}$. Um desequilíbrio entre estas vias culminará numa perda rápida e significativa de massa muscular, uma vez que $80 \%$ das proteínas do músculo esquelético são proteínas miofibrilares ${ }^{(11,42,60,95)}$.

Chopard et al. ${ }^{(16)}$ efectuaram uma análise quantitativa do teor proteico relativo em diferentes compartimentos do citoesqueleto e observaram diferentes alterações dependendo do tipo de músculo, da duração da suspensão do membro traseiro e da localização da proteína. Por exemplo, verificaram uma diminuição em 17 e $24 \%$ de actina e miosina, respectivamente, no músculo soleus após 6 semanas de suspensão do membro traseiro, o que confirma a maior susceptibilidade à inactividade e/ou ausência de carga deste músculo comparativamente com um músculo mais rápido como o EDL. Na desnervação, à semelhança da suspensão do membro traseiro, $\mathrm{o}$ músculo soleus desenvolve uma maior atrofia do que o músculo EDL. Neste modelo experimental também é observada uma rápida diminuição da síntese proteica ${ }^{(45)} \mathrm{e}$ um aumento da proteólise no músculo soleus ${ }^{(36)}$.

Estudos com músculo esquelético de rato revelaram a existência de pelo menos 4 processos proteolíticos neste tecido: (a) uma via lisossomal mediada por proteases (catepsinas) localizadas nestes organelos; (b) um processo citosólico, dependente de $\mathrm{Ca}^{2+}$, que envolve proteases activadas por este ião (calpainas); (c) um processo dependente de ATP que foi demonstrado após a inibição das proteases lisossomais e $\mathrm{Ca}^{2+}$-dependentes e (d) uma via independente de energia mas cuja base bioquímica é ainda incerta (78, 89).

Efectivamente, no músculo soleus de rato observouse um aumento da actividade da catepsina $\mathrm{D}$, em $42 \%$ após 5 dias de microgravidade, da catepsina B, $\mathrm{B}+\mathrm{L}$ e da calpaina, em $111 \%, 92 \%$ e $180 \%$ respectivamente, após 9 dias de ausência de carga. A via lisossomal e a cálcio-dependente parecem constituir a menor parte da proteólise total que ocorre numa situação de ausência de carga ${ }^{(11)}$. A maioria da degradação proteica requer ATP e para a maioria das proteínas este processo envolve o cofactor polipeptídico ubiquitina e uma grande protease ATP-dependente, o proteassoma. Nesta via, a ubiquitina liga-se covalentemente à proteína substrato e esta modificação marca-a para ser rapidamente degradada pelo complexo proteassoma $26 \mathrm{~S}^{(11,77,85,89)}$. O aumento dos níveis de conjugados ubiquitina-proteína, observado em vários tipos de atrofia muscular, face ao aumento da quebra de tais proteínas pelos proteassomas, indica que a conjugação da ubiquitina às proteínas musculares é acelerada nestas condições catabólicas ${ }^{(53,77)}$. A activação deste sistema parece ser fulcral na degradação dos componentes miofibrilares observada na atrofia ${ }^{(78)}$ e ocorre após a actuação das calpaínas ${ }^{\left({ }^{(5)}\right)}$. Também o aumento do stress oxidativo pode acelerar a quebra da proteína muscular, uma vez que as proteínas modificadas oxidativamente são mais susceptíveis ao ataque proteolítico ${ }^{(63)}$.

Embora os sistemas de degradação proteica tenham vindo a ser extensamente estudados, os mediadores moleculares específicos de degradação relacionados com a atrofia só muito recentemente têm vindo a ser definidos bem como as vias sinalizadoras que controlam os diferentes processos que levam à degradação muscular. Solomon et al. ${ }^{(77)}$ e Bodine et $a l^{(10)}$ referem a importância de duas ligases da ubiquitina que podem ser utilizadas como marcadores de atrofia do músculo esquelético, dado que se 
observou que perturbações muito diferentes, desde desnervação a tratamentos com glucocorticóides, activam as mesmas vias proteolíticas subjacentes ao processo atrófico ${ }^{(10)}$.

As alterações coordenadas destes sistemas proteolíticos, cada um dos quais podendo induzir a proteólise de diferentes componentes celulares, poderão estar na base da atrofia muscular ${ }^{(36)}$. Contudo, o papel preciso destes sistemas degradativos na ruptura das diferentes proteínas musculares não está, ainda, completamente esclarecido ${ }^{(78)}$.

Por outro lado, a inibição da síntese proteica ocorre muito provavelmente ao nível da tradução, uma vez que a síntese de proteínas como a MHC I diminui, enquanto que os níveis de mRNA permanecem inalterados ${ }^{\left({ }^{45}\right)}$. Tem sido sugerido que a diminuição inicial da síntese proteica durante a ausência de peso é o resultado de uma velocidade reduzida da elongação da cadeia polipeptídica nascente ao nível ribossomal ${ }^{(63)}$. Esta diminuição da síntese precede o aumento da degradação proteica no músculo soleus de rato submetido a ausência de carga. A capacidade do músculo esquelético sob ausência de carga em modular a síntese proteica via tradução está entre as primeiras alterações na expressão genética no músculo soleus nesta situação ${ }^{(11)}$.

Para além das alterações ao nível da regulação da síntese e da degradação proteica, outros mecanismos alternativos têm sido colocados no sentido de explicar as alterações morfológicas, bioquímicas e funcionais subjacentes à atrofia muscular. A apoptose, por exemplo, parece predispor a ocorrência da atrofia muscular esquelética ${ }^{(66)}$.

\section{Apoptose vs necrose}

A apoptose é um processo de morte celular individual, regulado pela activação de determinados genes ${ }^{(71,76)}$. Algumas das características morfológicas da apoptose incluem a condensação nuclear e citoplasmática, a fragmentação da célula em corpos apoptóticos, que posteriormente são fagocitados, e a ausência de inflamação local (1, 2, 30, 37, 39, 50,54,68,71, 73, 76, 90, 92). Estas alterações são devidas à activação de endonucleases e de proteases citoplasmáticas, num processo modulado por vários genes reguladores com função pró- e anti-apoptótica ${ }^{(71,76,90)}$.
Embora, nas células em geral, a apoptose possa ocorrer por vários mecanismos (Figura 3), a mitocôndria tem sido implicada como um dos seus principais centros reguladores ${ }^{(26,37,68)}$. Tem sido sugerido que estímulos celulares endógenos, tais como níveis elevados de cálcio ou de espécies reactivas de oxigénio (ROS), possam desencadear a apoptose pela via dependente do citocromo $\mathrm{C}^{(26,68)}$. Outras vias requerem uma activação alternativa para iniciar a cascata das caspases (proteases asparto-específicas dependentes da cisteína) ${ }^{(26,50,68,70)}$, as principais responsáveis pelas maiores alterações bioquímicas e morfológicas que ocorrem durante a apoptose ${ }^{(70)}$. Por exemplo, a ligação do TNF- $\alpha$ (Factor de Necrose Tumoral) ao seu receptor celular pode induzir a apoptose numa célula pela activação da procaspase-8 a qual, por sua vez, cliva e activa a procaspase-3. Também o stress do retículo endoplasmático pode contribuir parcialmente para a apoptose ao libertar o cálcio para o citoplasma, activando assim a procaspase- 12 . A activação das caspases leva à reorganização do citoesqueleto, interrompe a replicação e reparação do DNA, quebra a estrutura nuclear e desintegra a célula em corpos apoptóticos ${ }^{(26)}$.

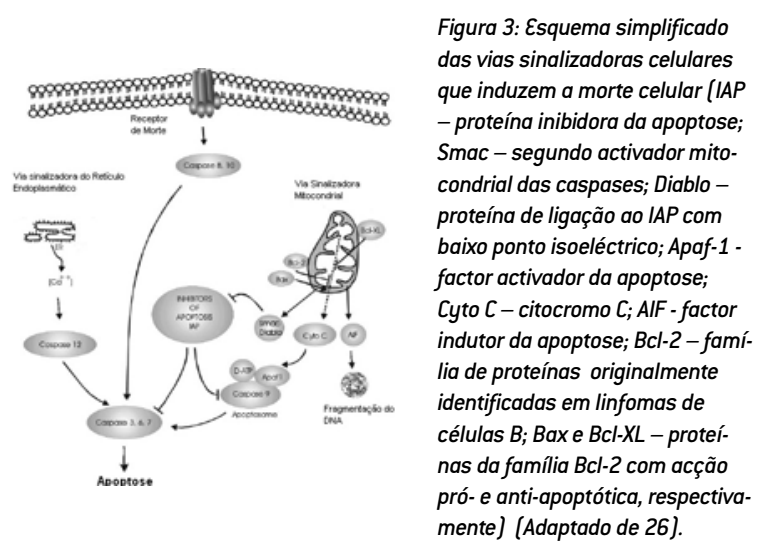

As fibras esqueléticas são únicas no facto de serem verdadeiramente multinucleadas ${ }^{(4,68)}$. A presença de múltiplos núcleos num citoplasma comum e não dividido levanta questões intrigantes relativamente ao possível papel dos mionúcleos na adaptação do músculo a exigências funcionais variáveis. Têm sur- 
gido alguns estudos que procuram analisar o papel dos mionúcleos na adaptação do músculo esquelético em situações de carga alterada ${ }^{(2,4)}$.

Numa fibra muscular esquelética, multinucleada, cada núcleo controla uma porção de fibra pela qual é rodeado numa relação designada domínio nuclear ${ }^{(3 .}$ ${ }^{27,44,60,76)}$, que consiste no volume de citoplasma da miofibra regulado pelos produtos dos genes de um dado mionúcleo ${ }^{\left({ }^{(6)}\right.}$. A diminuição do tamanho da fibra pode estar associada a uma diminuição do número total de mionúcleos (Figura $5 \mathrm{~A}$ e $\mathrm{B}$ ), a uma diminuição do tamanho de cada domínio mionuclear ou a ambos os efeitos. Alguns autores ${ }^{(4,76)}$ constataram que a diminuição do volume da fibra se deve a uma diminuição do tamanho do domínio mionuclear. Mais recentemente, Mitchell e Pavlath ${ }^{(60)}$ sugeriram que durante a atrofia, dado que as exigências transcripcionais e traducionais colocadas aos mionúcleos são atenuadas, as fibras respondem por eliminação dos mesmos, mantendo assim um domínio mionuclear constante. Alguns investigadores sugerem ainda que os mionúcleos individuais, em miofibras adultas de controlo ou em regeneração, são capazes de transcrição independente ${ }^{(4)}$. Tudo indica que a transcrição seja espaço-temporalmente distinta em mionúcleos individuais e que ocorra de uma forma estocástica ou pulsativa. Cada mionúcleo individual pode expressar proteínas diferentes das dos mionúcleos vizinhos, o que sugere que os mionúcleos respondem diferentemente a estímulos diversos ${ }^{(4)}$. Adicionalmente, constatou-se que a resposta mionuclear é específica do tipo de fibra. Diversos estudos ${ }^{(5,27,44)}$ registaram uma maior diminuição no número de mionúcleos em fibras que expressam MHC tipo I, relativamente às tipo II, numa situação de carga diminuída. A análise de vários dados experimentais sugerem que uma diminuição no número de mionúcleos pode preceder uma mudança completa da expressão de MHC lentas para rápidas (Figura 4).

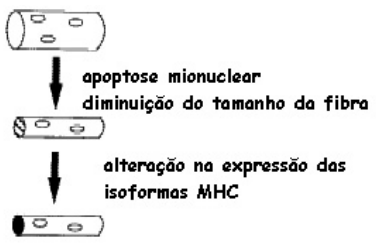

Figura 4: Alterações no tamanho da fibra, no número de mionúcleos e expressão genética durante a atrofia da fibra muscular (Adaptado de 4).
Os mecanismos responsáveis pela perda de mionúcleos durante condições de atrofia muscular não estão bem definidos, nem é claro como é que os mionúcleos individuais podem ser eliminados sem a destruição de todos os núcleos ou de toda a miofibra. Os resultados de estudos recentes ${ }^{(12,14)}$ mostraram que, na desnervação permanente a longo termo, a morte celular necrótica e apoptótica ocorre a uma velocidade significativa, contribuindo para a atrofia muscular. A apoptose, que se caracteriza pela destruição regulada do núcleo, está envolvida na remodelação de tecidos durante situações fisiológicas, tais como o desenvolvimento embrionário e o controlo do número de células em tecidos proliferativos, e durante estados patológicos, tais como a doença e a lesão ${ }^{(1,4)}$. No entanto, a definição da importância relativa da apoptose nuclear na fibra muscular é substancialmente complicada pela presença de centenas de mionúcleos em cada fibra muscular. Alguns núcleos, numa única célula, podem ser marcados para a morte enquanto outros poderão não ser afectados ${ }^{(1)}$. Então, uma forma modificada de "morte nuclear" com a destruição do domínio correspondente sem a subsequente destruição total da fibra, poderá ser responsável pela eliminação de mionúcleos das fibras multinucleadas ${ }^{(1,4,12,27,68)}$. Mesmo antes do termo "apoptose" ter sido introduzido na ciência era descrita uma série de anormalidades ultraestruturais mionucleares após a desnervação a longo-termo, que incluía a condensação da cromatina, a contracção e a fragmentação nuclear ${ }^{(1)}$. De facto, a apoptose de mionúcleos individuais tem sido registada numa série de estados patológicos musculares; por exemplo, foi observada em ratinhos $m d x$ distróficos ${ }^{(71)}$ e no músculo esquelético de ratos com insuficiência cardíaca ${ }^{(55,93)}$. Allen et al. ${ }^{(4)}$ quantificaram a incidência de núcleos positivos por marcação TDT (terminal desoxinucleotidil transferase) um indicador da fragmentação da dupla cadeia do DNA sugestiva da apoptose, em músculos soleus de ratos controlo e com suspensão do membro traseiro. O número de núcleos TDT positivos total era significativamente maior em ratos com suspensão do membro traseiro relativamente ao controlo. Também utilizando microscopia confocal, foi observado um número significativamente maior de mionúcleos morfologicamente anormais em músculos de ratos com suspen- 
são do membro traseiro ${ }^{(60)}$. Estas observações, juntamente com outras de estudos utilizando marcadores nucleares apoptóticos, suportam a hipótese de que a eliminação apoptótica dos mionúcleos constitui um mecanismo que contribui para a diminuição do número dos mesmos observada durante a atrofia da fibra muscular esquelética ${ }^{(60,90)}$. No músculo soleus de ratos com insuficiência cardíaca, o número de núcleos apoptóticos nas fibras e nas células intersticiais aumenta (Figuras 4 e 5). Este fenómeno é acompanhado por um aumento dos níveis de caspase-3 e por uma diminuição dos níveis de $\mathrm{Bcl}-2^{(55)}$, uma importante proteína anti-apoptótica, envolvida na regulação da libertação do citocromo $\mathrm{C}$ pela mito-

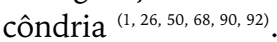
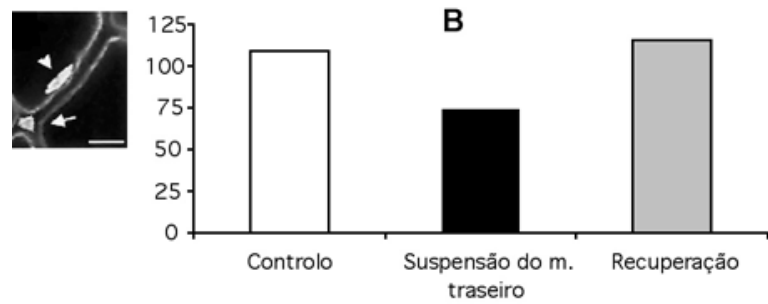

Figura 5: 0 número de mionúcleos no soleus diminui após 2 semanas de suspensão do membro traseiro. A: imagem representativa de marcação nuclear. $B$ : número de mionúcleos em músculo soleus controlo, após 2 semanas de suspensão de membro traseiro e após 2 semanas de recuperação. (Adaptado de 60).

Embora algumas proteínas solúveis não sejam reguladas por um domínio, a miosina é limitada ao seu domínio nuclear. Este conceito é muito importante na explicação e interpretação das desordens musculares e na expressão genética destas células ${ }^{(44)}$. A diminuição da actividade transcripcional, observada em situações de microgravidade, pode resultar de uma redução da actividade transcripcional por mionúcleo, de uma diminuição do número de mionúcleos por fibra ou de ambos os efeitos ${ }^{(1,5)}$.

Primeau et al. ${ }^{(68)}$ sugerem que, no músculo humano, as fibras tipo I estão mais protegidas da ocorrência de apoptose pelo facto de terem um maior teor mitocondrial e, consequentemente, um maior índice de Bcl-2. No entanto, este efeito poderá ser contra- riado pela maior velocidade de produção de ROS que se verifica neste tipo de fibras. Efectivamente, as fibras tipo I evidenciam um maior grau de atrofia relativamente às tipo II, numa situação de ausência de carga ${ }^{(44,68)}$. Alguns estudos mostram um maior número de núcleos em fibras lentas comparativamente às rápidas, o que pode estar relacionado com uma maior velocidade de turnover proteico que ocorre nas fibras tipo I. Nos mamíferos, estas fibras são as primeiras a serem recrutadas entre os vários tipos de fibras, resultando numa maior carga metabólica para as fibras tipo I relativamente às tipo II, o que talvez requeira um maior controlo nuclear (e correspondentemente um domínio menor) do que nas fibras rápidas tipo II, que são menos frequentemente recrutadas ${ }^{(44)}$. Por outro lado, alguns autores ${ }^{(55,93)}$ verificaram que, em sujeitos com insuficiência cardíaca, os músculos rápidos são mais susceptíveis à ocorrência de apoptose.

O aumento na coexpressão MHC em fibras de músculo soleus, verificado após o voo espacial e suspensão do membro traseiro, representa um passo na transformação das fibras musculares de lentas para rápidas. No entanto, desconhece-se se a coexpressão observada por Allen et al. ${ }^{(5)}$ é devida à coexpressão de todas as MHCs por todos os mionúcleos, se é devida a uma expressão heterogénea das diferentes MHCs por diferentes mionúcleos ao longo da fibra ou se é devida à conversão de todos os mionúcleos para expressão da nova MHC, antes da degradação completa da MHC original. Os resultados de Allen et al. ${ }^{(5)}$ sugerem que aproximadamente $19 \%$ das fibras dos animais submetidos a voo espacial expressam alguma MHC neonatal nas fibras que também expressam MHC adultas. Porque estas fibras não são significativamente diferentes em tamanho das fibras controlo, é provável que sejam fibras reexpressando MHC neonatal. Esta reexpressão de uma isoforma MHC de desenvolvimento pode ser devida à fusão de células satélite às fibras existentes, embora esta possibilidade não seja defendida por alguns autores, que sugerem que a expressão de MHC neonatal reflecte uma reexpressão de mionúcleos adultos existentes ${ }^{(5)}$. Por exemplo, Dupont-Versteegden et al. ${ }^{(27)}$ defendem que os sinais que promovem a activação das células satélite numa situação de isolamento da espinal medula são pouco claros dado que não ocorre 
uma lesão muscular clara. Mozdiak et al. ${ }^{(62)}$ verificaram que a suspensão do membro traseiro reduz a actividade mitótica das células satélite, inibe a expansão do tamanho da unidade de DNA e induz a atrofia no músculo esquelético.

A indução de lesões estruturais, necrose, inflamação e deterioração funcional é observada quando o músculo é submetido a modificações de carga mecânica ${ }^{(12)}$. A necrose é um processo de morte celular que se caracteriza por uma extensa tumefacção e lise celular decorrente de agressões não fisiológicas agudas e acidentais ${ }^{(33,50,68,90)}$. A magnitude do insulto inicial, mais do que o próprio tipo de estímulo, parece ser decisivo na via de morte celular que a célula segue ${ }^{(33)}$. A mitocôndria parece desempenhar um papel fulcral na activação da via necrótica, ou da via apoptóti$\mathrm{ca}$, de degradação nuclear e celular ${ }^{(68,76)}$. Por exemplo, na distrofia muscular de Duchenne (DMD), que ocorre devido a uma deficiência de distrofina, observa-se uma morfologia aberrante da mitocôndria, bem como uma elevação patológica dos níveis de cálcio intracelular e inflamação tecidual, características que implicam a necrose na ocorrência de atrofia muscular nesta distrofia ${ }^{(1)}$. No entanto, os mecanismos subjacentes à invasão de células inflamatórias e subsequente necrose muscular nestas situações não estão completamente esclarecidos ${ }^{(12)}$. A possibilidade de a invasão das células inflamatórias contribuírem para a lesão muscular numa situação de atrofia muscular é suportada pela observação da elevação significativa da concentração de neutrófilos e de macrófagos que ocorre em períodos de tempo em que se observam sinais estruturais de lesão e necrose da fibra ${ }^{(8,12,48)}$.

Borisov e Carlson ${ }^{(12)}$ sugeriram que mais do que um mecanismo de morte celular pode estar envolvido na desnervação do músculo esquelético e que a contribuição individual destes mecanismos para a atrofia muscular sofre alterações durante o decorrer da desnervação a longo prazo. Formigli et al. ${ }^{(33)}$ sugerem que a apoptose e a necrose não têm de ser necessariamente duas vias independentes, mas podem apresentar eventos comuns, relativamente à via de tradução de sinal e nas fases iniciais do processo de morte celular. Os mesmos autores observaram ainda, em culturas de células expostas a estímulos hipóxicos severos, uma forma de morte celular intermédia entre a apoptose e a necrose, mais do que uma necrose verdadeira.

Uma exacerbação na lesão muscular é aparentemente iniciada por um aumento do stress mecânico e consequente invasão por células inflamatórias por reposição da carga após o processo atrófico.

Observações morfológicas obtidas in vitro e in vivo indicam que os leucócitos podem, de facto, acentuar a lesão muscular por libertarem radicais livres e/ou enzimas proteolíticas ${ }^{(34)}$. Frenette et al. ${ }^{\left({ }^{35)} \text {, concluí- }\right.}$ ram ainda que, no modelo de suspensão do membro traseiro seguido de reposição de carga, o aumento da concentração de células inflamatórias não está associado a qualquer diminuição da força muscular e que a incapacidade de activar a maquinaria contráctil constitui o mecanismo primário para a perda de produção de força logo após a reposição da carga.

Frenette et al. ${ }^{(34)}$ verificaram ainda que a lesão muscular, que ocorre após a restauração da carga, resulta em parte da activação do sistema de complemento.

\section{0 papel regulador das HSP}

As proteínas de choque térmico (HSP) têm um papel importante em vários processos celulares, nomeadamente na atrofia, ao ligarem-se a proteínas inactivas ou mal formadas e ao prevenir a sua agregação, promovendo assim a renaturação das mesmas ${ }^{(30,37,54,63)} \mathrm{e}$ protegendo as células de estímulos indutores de morte celular ${ }^{(37,54)}$. No entanto, quando as HSP são sobre-reguladas podem induzir a morte celular por apoptose, em vez da morte necrótica, promovendo a tolerância. Se são sobre-reguladas e libertadas durante a necrose, então induzem uma acentuada resposta imune ${ }^{(30)}$.

Estas proteínas são altamente conservadas entre as espécies e são caracterizadas por um rápido aumento na sua expressão quando as células são expostas a condições de stress como, por exemplo, aumento da temperatura, hipoxia, isquemia, privação de glucose, contacto com metais pesados ou venenos metabóli$\cos { }^{(30,65)}$. No músculo esquelético são expressas várias HSPs com diferentes funções, nomeadamente HSPs pequenas (como a ubiquitina que participa na degradação proteica, a alpha $\beta$-cristalina, a HSP20 e a HSP27), HSP70, HSP60 e HSP90 ${ }^{(30)}$.

A indução das HSPs difere com o tipo de fibra muscular, o que sugere que a expressão destas proteínas 
é específica do tipo de fibra muscular. Os mecanismos moleculares de indução, regulação das HSPs e o seu papel na manutenção da função muscular não estão completamente compreendidos ${ }^{(56)}$. A HSP70, por exemplo, funciona como um mecanismo protector contra a perda de fibra muscular ao inibir a apoptose ${ }^{(26)}$. Também previne a degradação da proteína muscular durante os períodos de reduzida actividade contráctil ${ }^{(63,65)}$. Neste processo é de salientar a HSP72, a forma induzível da família HSP70, que parece ter um papel activo na restauração de proteínas danificadas da fibra muscular ${ }^{(37,65)}$. Oishi et al. ${ }^{\left({ }^{65)}\right.}$ sugeriram que a HSP70 pode mediar a velocidade de elongação do polipéptido nascente e a subsequente velocidade de síntese proteica no músculo soleus após suspensão do membro traseiro.

A expressão das HSP, para além de ser específica dos órgãos e tecidos, também é específica do tipo de fibra muscular. Por exemplo, o teor de HSP20 aumenta rapidamente durante o desenvolvimento do rato mas diminui após desnervação, levando à perda das fibras de contracção lenta. A Alpha $\beta$-cristalina é abundantemente expressa em tecidos com elevada capacidade oxidativa e pensa-se que desempenha um papel importante ao nível do desenvolvimento e da funcionalidade muscular ${ }^{(56)}$. Contudo, o tipo de HSP mais induzida pelo stress pertence à família HSP70. Na musculatura de ratos não stressados e sedentários, os níveis de HSP72 são significativamente diferentes entre os diferentes músculos e parecem estar relacionados com a percentagem de fibras oxidativas lentas ${ }^{\left({ }^{65}\right)}$. Estudos sobre a expressão destas HSPs e a especificidade da fibra muscular mostram que a HSP72 é expressa constitutivamente em músculos de rato compostos por fibras musculares do tipo I mas não nos que compreendem fibras tipo II. Nos músculos com fibras mistas, o teor em HSP70 é grosseiramente proporcional ao teor em fibras tipo I, o que sugere que a expressão de HSP70 é específica das fibras musculares tipo I ${ }^{(56)}$. Por essa razão, são os músculos lentos, como o soleus, que apresentam os maiores níveis de HSP72 em ratos com suspensão do membro traseiro ${ }^{(65)}$.

Situações que induzam um aumento da expressão das HSP72, como a hipertermia, conferem alguma protecção contra a atrofia do músculo esquelético induzida por suspensão do membro traseiro. Estas simples contramedidas podem ter potenciais aplicações na redução da atrofia muscular devida, por exemplo, ao voo espacial ${ }^{(63)}$, bem como no tratamento de algumas patologias como o cancro ou doenças autoimunes ${ }^{(54)}$.

\section{CONCLUSÕES}

O músculo esquelético pode ser visto como uma estrutura dinâmica uma vez que as suas células alteram as propriedades em função das exigências funcionais ${ }^{(72,84)}$. Durante os últimos 30 anos tem-se notado um interesse crescente no papel do suporte postural e da actividade neuromuscular na regulação das propriedades estruturais, funcionais, bioquímicas e moleculares do músculo esquelético ${ }^{(42)}$. Para o efeito, têm sido utilizados vários modelos experimentais, salientando-se a desnervação, a suspensão do membro traseiro, o isolamento da espinal medula e o voo espacial ${ }^{(18,19,42,51)}$. Estes modelos resultam numa acentuada atrofia dos músculos extensores rápidos e lentos e na transformação das fibras fenotipicamente lentas para rápidas ${ }^{(42)}$, acompanhada por um aumento acentuado do metabolismo glicolítico ${ }^{(19)}$.

O debate das possíveis causas de atrofia muscular esquelética continua em aberto. Várias hipóteses têm sido levantadas, desde perda da função anabólica a alterações do fluxo sanguíneo e activação de citocinas como o TNF- $\alpha^{(66,93)}$. Efectivamente, a perda acentuada de proteína e de massa muscular que caracteriza a atrofia parece resultar de um severo desequilíbrio entre as vias de síntese e de degradação proteica. A este nível é de salientar o papel das calpaínas e do complexo ubiquitina-proteassoma ${ }^{(78,85)}$.

A atrofia muscular é acompanhada por uma redução do número médio de mionúcleos por fibra. A apoptose parece estar subjacente a esta eliminação regulada de mionúcleos ${ }^{(1,2)}$. No entanto, a ocorrência de necrose também tem sido associada à atrofia em determinadas situações como, por exemplo, na desnervação a longo termo ou na Distrofia Muscular de Duchenne ${ }^{(1,12,14)}$. É ainda de salientar a aparente importância das HSPs na manutenção da função muscular numa situação de atrofia ${ }^{(56)}$. 


\section{CORRRESPONDÊNCIA}

\section{Rita Ferreira}

Faculdade de Ciências do Desporto

e de Educação Física

Universidade do Porto

Rua Dr. Plácido Costa, 91

4200-450 Porto, Portugal

rmferreira@fcdef.up.pt

\section{REFERÊNCIAS}

1. Adams V, Gielen S, Hambrecht R, Schuler G (2001). Apoptosis in skeletal muscle. Front Biosci 6 D1-D11.

2. Allen DL, Linderman JK, Roy RR, Bigbee AJ, Grindeland RE, Mukku V, Edgerton VR (1997). Apoptosis: a mechanism contributing to remodeling of skeletal muscle in response to hindlimb unweighting. Am J Physiol 273 (2 Pt 1): C579-587.

3. Allen DL, Monke SR, Talmadge RJ, Roy RR, Edgerton VR (1995). Plasticity of myonuclear number in hypertrophied and atrophied mammalian skeletal muscle fibers. $J$ Appl Physiol 78 (5): 1969-1976.

4. Allen DL, Roy RR, Edgerton VR (1999). Myonuclear domains in muscle adaptation and disease. Muscle Nerve 22 (10): 1350-1360.

5. Allen DL, Yasui W, Tanaka T, Ohira Y, Nagaoka S, Sekiguchi C, Hinds WE, Roy RR, Edgerton VR (1996). Myonuclear number and myosin heavy chain expression in rat soleus single muscle fibers after spaceflight. J Appl Physiol 81 (1): 145-151

6. Andersen JL, Gruschy-Knudsen T, Sandri C, Larsson L, Schiaffino S (1999). Bed rest increases the amount of mismatched fibers in human skeletal muscle. J Appl Physiol 86 (2): $455-460$

7. Appell HJ (1986). Skeletal muscle atrophy during immobilization. Int $J$ Sports Med 7 (1): 1-5

8. Appell HJ (1990). Muscular atrophy following immobilisation. A review. Sports Med 10 (1): 42-58

9. Baldwin KM, Haddad F (2001). Effects of different activity and inactivity paradigms on myosin heavy chain gene expression in striated muscle. J Appl Physiol 90 (1): 345-357

10. Bodine SC, Latres E, Baumhueter S, Lai VK, Nunez L, Clarke BA, Poueymirou WT, Panaro FJ, Na E, Dharmarajan K, Pan ZQ, Valenzuela DM, DeChiara TM, Stitt TN, Yancopoulos GD, Glass DJ (2001). Identification of ubiquitin ligases required for skeletal muscle atrophy. Science 294 (5547): 1704-1708

11. Booth FW, Criswell DS (1997). Molecular events underlying skeletal muscle atrophy and the development of effective countermeasures. Int J Sports Med 18 Suppl 4 S265-269

12. Borisov AB, Carlson BM (2000). Cell death in denervated skeletal muscle is distinct from classical apoptosis. Anat Rec 258 (3): 305-318

13. Caiozzo VJ, Haddad F, Baker MJ, Herrick RE, Prietto N, Baldwin KM (1996). Microgravity-induced transformations of myosin isoforms and contractile properties of skeletal muscle. J Appl Physiol 81 (1): 123-132

14. Carraro U, Rossini, K., Zanin, M.E., Rizzi, C., Mayr, W., Kern, H. (2002). Induced myogenesis in long-term permanent denervation: perspective role in functional electrical stimulation of denervated legs in humans. Basic Applied Myology 12 53-63

15. Castro MJ, Apple DF, Jr., Staron RS, Campos GE, Dudley GA (1999). Influence of complete spinal cord injury on skeletal muscle within 6 mo of injury. J Appl Physiol 86 (1): 350-358

16. Chopard A, Pons F, Marini JF (2001). Cytoskeletal protein contents before and after hindlimb suspension in a fast and slow rat skeletal muscle. Am J Physiol Regul Integr Comp Physiol 280 (2): R323-330

17. Cohen I, Bogin E, Chechick A, Rzetelny V (1999). 
Biochemical alterations secondary to disuse atrophy in the rat's serum and limb tissues. Arch Orthop Trauma Surg 119 (7-8): 410-417

18. Connor MK, Hood DA (1998). Effect of microgravity on the expression of mitochondrial enzymes in rat cardiac and skeletal muscles. J Appl Physiol 84 (2): 593-598

19. Cros N, Muller J, Bouju S, Pietu G, Jacquet C, Leger JJ, Marini JF, Dechesne CA (1999). Upregulation of M-creatine kinase and glyceraldehyde3-phosphate dehydrogenase: two markers of muscle disuse. Am J Physiol 276 (2 Pt 2): R308-316

20. Czerwinski SM, Novakofski J, Bechtel PJ (1993). Is insulin-like growth factor gene expression modulated during cardiac hypertrophy? Med Sci Sports Exerc 25 (4): 495-500

21. D'Antona G, Pellegrino, M.A., Rossi, R., Carlizzi, C.N., Reggiani, C., Bottinelli, R. (2000). Disuse induced-atrophy and contractile impairment of human skeletal muscle fibres. Basic Applied Myology 10 27-32

22. Darr KC, Schultz E (1989). Hindlimb suspension suppresses muscle growth and satellite cell proliferation. J Appl Physiol 67 (5): 1827-1834

23. Degens H, Veerkamp JH (1994). Changes in oxidative capacity and fatigue resistance in skeletal muscle. Int $J$ Biochem 26 (7): 871-878

24. Deschenes MR, Giles JA, McCoy RW, Volek JS, Gomez AL, Kraemer WJ (2002). Neural factors account for strength decrements observed after short-term muscle unloading. Am J Physiol Regul Integr Comp Physiol 282 (2): R578-583

25. di Prampero PE, Narici MV (2003). Muscles in microgravity: from fibres to human motion. J Biomech 36 (3): 403-412

26. Dirks A, Leeuwenburgh C (2002). Apoptosis in skeletal muscle with aging. Am J Physiol Regul Integr Comp Physiol 282 (2): R519-527

27. Dupont-Versteegden EE, Murphy RJ, Houle JD, Gurley CM, Peterson CA (1999). Activated satellite cells fail to restore myonuclear number in spinal cord transected and exercised rats. Am J Physiol 277 (3 Pt 1): C589-597

28. Edgerton VR, Roy RR, Allen DL, Monti RJ (2002). Adaptations in skeletal muscle disuse or decreased-use atrophy. Am J Phys Med Rehabil 81 (11 Suppl): S127-147

29. Edgerton VR, Zhou MY, Ohira Y, Klitgaard H, Jiang B, Bell G, Harris B, Saltin B, Gollnick PD, Roy RR, et al. (1995). Human fiber size and enzymatic properties after 5 and 11 days of spaceflight. J Appl Physiol 78 (5): 1733-1739

30. Fehrenbach E, Northoff $\mathrm{H}$ (2001). Free radicals, exercise, apoptosis, and heat shock proteins. Exerc Immunol Rev 7 66-89

31. Fitts RH, Riley DR, Widrick JJ (2001). Functional and structural adaptations of skeletal muscle to microgravity. $J$ Exp Biol 204 (Pt 18): 3201-3208

32. Fluckey JD, Dupont-Versteegden EE, Montague DC, Knox M, Tesch P, Peterson CA, Gaddy-Kurten D (2002). A rat resistance exercise regimen attenuates losses of musculoskeletal mass during hindlimb suspension. Acta Physiol Scand 176 (4): 293-300

33. Formigli L, Papucci L, Tani A, Schiavone N, Tempestini A, Orlandini GE, Capaccioli S, Orlandini SZ (2000). Aponecrosis: morphological and biochemical exploration of a syncretic process of cell death sharing apoptosis and necrosis. J Cell Physiol 182 (1): 41-49

34. Frenette J, Cai B, Tidball JG (2000). Complement activa- tion promotes muscle inflammation during modified muscle use. Am J Pathol 156 (6): 2103-2110

35. Frenette J, St-Pierre M, Cote CH, Mylona E, Pizza FX (2002). Muscle impairment occurs rapidly and precedes inflammatory cell accumulation after mechanical loading. Am J Physiol Regul Integr Comp Physiol 282 (2): R351-357

36. Furuno K, Goodman MN, Goldberg AL (1990). Role of different proteolytic systems in the degradation of muscle proteins during denervation atrophy. J Biol Chem 265 (15): 8550-8557

37. Gabai VL, Sherman MY (2002). Invited review: Interplay between molecular chaperones and signaling pathways in survival of heat shock. J Appl Physiol 92 (4): 1743-1748

38. Gamrin L, Berg HE, Essen P, Tesch PA, Hultman E, Garlick PJ, McNurlan MA, Wernerman J (1998). The effect of unloading on protein synthesis in human skeletal muscle. Acta Physiol Scand 163 (4): 369-377

39. Gastman BR (2001). Apoptosis and its clinical impact. Head Neck 23 (5): 409-425

40. Grichko VP, Gettelman GJ, Widrick JJ, Fitts RH (1999). Substrate and enzyme profile of fast and slow skeletal muscle fibers in rhesus monkeys. J Appl Physiol 86 (1): 335-340

41. Haddad F, Qin AX, Zeng M, McCue SA, Baldwin KM (1998). Interaction of hyperthyroidism and hindlimb suspension on skeletal myosin heavy chain expression. J Appl Physiol 85 (6): 2227-2236

42. Haddad F, Roy RR, Zhong H, Edgerton VR, Baldwin KM (2003). Atrophy responses to muscle inactivity. II. Molecular markers of protein deficits. J Appl Physiol 95 (2): 791-802

43. Harridge SD (2003). Ageing and local growth factors in muscle. Scand J Med Sci Sports 13 (1): 34-39

44. Hikida RS, Van Nostran S, Murray JD, Staron RS, Gordon SE, Kraemer WJ (1997). Myonuclear loss in atrophied soleus muscle fibers. Anat Rec 247 (3): 350-354

45. Hornberger TA, Hunter RB, Kandarian SC, Esser KA (2001). Regulation of translation factors during hindlimb unloading and denervation of skeletal muscle in rats. $\mathrm{Am} \mathrm{J}$ Physiol Cell Physiol 281 (1): C179-187

46. Hortobagyi T, Dempsey L, Fraser D, Zheng D, Hamilton G, Lambert J, Dohm L (2000). Changes in muscle strength, muscle fibre size and myofibrillar gene expression after immobilization and retraining in humans. $J$ Physiol 524 Pt 1 293-304

47. Kano Y, Shimegi S, Takahashi H, Masuda K, Katsuta S (2000). Changes in capillary luminal diameter in rat soleus muscle after hind-limb suspension. Acta Physiol Scand 169 (4): 271-276

48. Kasper CE, Talbot LA, Gaines JM (2002). Skeletal muscle damage and recovery. AACN Clin Issues 13 (2): 237-247

49. Kauhanen S, Leivo I, Michelsson JE (1993). Early muscle changes after immobilization. An experimental study on muscle damage. Clin Orthop (297): 44-50

50. Kidd VJ (1998). Proteolytic activities that mediate apoptosis. Annu Rev Physiol 60 533-573

51. Kondo (2000). Oxidative stress in muscular atrophy. In CK Sen, Packer, L., Hanninen, O., Handbook of oxidants and antioxidants in exercise, Amsterdam: Elsevier, 631-652

52. Larsson L, Li X, Berg HE, Frontera WR (1996). Effects of removal of weight-bearing function on contractility and myosin isoform composition in single human skeletal 
muscle cells. Pflugers Arch 432 (2): 320-328

53. Lecker SH, Solomon V, Mitch WE, Goldberg AL (1999). Muscle protein breakdown and the critical role of the ubiquitin-proteasome pathway in normal and disease states. $J$ Nutr 129 (1S Suppl): 227S-237S

54. Li CY, Lee JS, Ko YG, Kim JI, Seo JS (2000). Heat shock protein 70 inhibits apoptosis downstream of cytochrome $c$ release and upstream of caspase-3 activation.J Biol Chem 275 (33): 25665-25671

55. Libera LD, Zennaro R, Sandri M, Ambrosio GB, Vescovo $\mathrm{G}$ (1999). Apoptosis and atrophy in rat slow skeletal muscles in chronic heart failure. Am J Physiol 277 (5 Pt 1): C982-986

56. Liu Y, Steinacker JM (2001). Changes in skeletal muscle heat shock proteins: pathological significance. Front Biosci 6 D12-25

57. Lu DX, Huang SK, Carlson BM (1997). Electron microscopic study of long-term denervated rat skeletal muscle. Anat Rec 248 (3): 355-365

58. McDonald KS, Fitts RH (1995). Effect of hindlimb unloading on rat soleus fiber force, stiffness, and calcium sensitivity. J Appl Physiol 79 (5): 1796-1802

59. Michael K (2000). Relationship of skeletal muscle atrophy to functional status: a systematic research review. Biol Res Nurs 2 (2): 117-131

60. Mitchell PO, Pavlath GK (2001). A muscle precursor celldependent pathway contributes to muscle growth after atrophy. Am J Physiol Cell Physiol 281 (5): C1706-1715

61. Morey-Holton ER, Globus RK (2002). Hindlimb unloading rodent model: technical aspects. J Appl Physiol 92 (4): 1367-1377

62. Mozdziak PE, Pulvermacher PM, Schultz E (2001). Muscle regeneration during hindlimb unloading results in a reduction in muscle size after reloading. $J$ Appl Physiol 91 (1): $183-190$

63. Naito H, Powers SK, Demirel HA, Sugiura T, Dodd SL, Aoki J (2000). Heat stress attenuates skeletal muscle atrophy in hindlimb-unweighted rats. J Appl Physiol 88 (1): 359-363

64. Ohira Y, Yoshinaga T, Ohara M, Nonaka I, Yoshioka T, Yamashita-Goto K, Shenkman BS, Kozlovskaya IB, Roy RR, Edgerton VR (1999). Myonuclear domain and myosin phenotype in human soleus after bed rest with or without loading. J Appl Physiol 87 (5): 1776-1785

65. Oishi Y, Ishihara A, Talmadge RJ, Ohira Y, Taniguchi K, Matsumoto H, Roy RR, Edgerton VR (2001). Expression of heat shock protein 72 in atrophied rat skeletal muscles. Acta Physiol Scand 172 (2): 123-130

66. Persinger R, Janssen-Heininger $Y$, Wing SS, Matthews DE, LeWinter MM, Toth MJ (2003). Effect of heart failure on the regulation of skeletal muscle protein synthesis, breakdown, and apoptosis. Am J Physiol Endocrinol Metab 284 (5): E1001-1008

67. Pollack M, Leeuwenburgh C (1999). Molecular mechanisms of oxidative stress in aging: free radicals, aging, antioxidants and disease. In CK Sen, L Packer, O Hanninen, Handbook of oxidants and antioxidants in exercise. Basel: Elsevier science B.V., 881-923

68. Primeau AJ, Adhihetty PJ, Hood DA (2002). Apoptosis in heart and skeletal muscle. Can J Appl Physiol 27 (4): 349-395

69. Putman CT, Sultan KR, Wassmer T, Bamford JA, Skorjanc D, Pette D (2001). Fiber-type transitions and satellite cell activation in low-frequency-stimulated muscles of young and aging rats. J Gerontol A Biol Sci Med Sci 56 (12): B510-519

70. Rehm M, Dussmann H, Janicke RU, Tavare JM, Kogel D, Prehn JH (2002). Single-cell fluorescence resonance energy transfer analysis demonstrates that caspase activation during apoptosis is a rapid process. Role of caspase-3. J Biol Chem 277 (27): 24506-24514

71. Rossini K DA, Sandri M, Destro $C$, Donà $M$, Carraro U (2000). Time-Course of Exercise and Apoptosis in Dystrophin-deficient Muscle of Mice. Basic Applied Myology 10 (1\&2): $33-38$

72. Saitoh A, Okumoto T, Nakano H, Wada M, Katsuta S (1999). Age effect on expression of myosin heavy and light chain isoforms in suspended rat soleus muscle. J Appl Physiol 86 (5): 1483-1489

73. Sandri M, Carraro U, Podhorska-Okolov M, Rizzi C, Arslan P, Monti D, Franceschi C (1995). Apoptosis, DNA damage and ubiquitin expression in normal and mdx muscle fibers after exercise. FEBS Lett 373 (3): 291-295

74. Schmalbruch H, Lewis DM (2000). Dynamics of nuclei of muscle fibers and connective tissue cells in normal and denervated rat muscles. Muscle Nerve 23 (4): 617-626

75. Schwartz LM, Ruff RL (2002). Changes in contractile properties of skeletal muscle during developmentally programmed atrophy and death. Am J Physiol Cell Physiol 282 (6): C1270-1277

76. Smith HK, Maxwell L, Martyn JA, Bass JJ (2000). Nuclear DNA fragmentation and morphological alterations in adult rabbit skeletal muscle after short-term immobilization. Cell Tissue Res 302 (2): 235-241

77. Solomon V, Baracos V, Sarraf P, Goldberg AL (1998). Rates of ubiquitin conjugation increase when muscles atrophy, largely through activation of the N-end rule pathway. Proc Natl Acad Sci U S A 95 (21): 12602-12607

78. Solomon V, Goldberg AL (1996). Importance of the ATPubiquitin-proteasome pathway in the degradation of soluble and myofibrillar proteins in rabbit muscle extracts. J Biol Chem 271 (43): 26690-26697

79. Sorichter S, Mair J, Koller A, Gebert W, Rama D, Calzolari C, Artner-Dworzak E, Puschendorf B (1997). Skeletal troponin I as a marker of exercise-induced muscle damage. J Appl Physiol 83 (4): 1076-1082

80. St Pierre BA, Tidball JG (1994). Differential response of macrophage subpopulations to soleus muscle reloading after rat hindlimb suspension. J Appl Physiol 77 (1): 290-297

81. St-Amand J, Okamura K, Matsumoto K, Shimizu S, Sogawa Y (2001). Characterization of control and immobilized skeletal muscle: an overview from genetic engineering. Faseb J 15 (3): 684-692

82. Stein TP, Schluter MD, Moldawer LL (1999). Endocrine relationships during human spaceflight. Am J Physiol 276 (1 Pt 1): E155-162

83. Stevens L, Gohlsch B, Mounier Y, Pette D (1999). Changes in myosin heavy chain mRNA and protein isoforms in single fibers of unloaded rat soleus muscle. FEBS Lett 463 (1-2): 15-18

84. Stevens L, Sultan KR, Peuker H, Gohlsch B, Mounier Y, Pette D (1999). Time-dependent changes in myosin heavy chain mRNA and protein isoforms in unloaded soleus muscle of rat. Am J Physiol 277 (6 Pt 1): C1044-1049

85. Sultan KR, Dittrich BT, Pette D (2000). Calpain activity in 
fast, slow, transforming, and regenerating skeletal muscles of rat. Am J Physiol Cell Physiol 279 (3): C639-647

86. Talmadge RJ (2000). Myosin heavy chain isoform expression following reduced neuromuscular activity: potential regulatory mechanisms. Muscle Nerve 23 (5): 661-679

87. Talmadge RJ, Roy RR, Caiozzo VJ, Edgerton VR (2002). Mechanical properties of rat soleus after long-term spinal cord transection. J Appl Physiol 93 (4): 1487-1497

88. Talmadge RJ, Roy RR, Edgerton VR (1996). Distribution of myosin heavy chain isoforms in non-weight-bearing rat soleus muscle fibers. J Appl Physiol 81 (6): 2540-2546

89. Tawa NE, Jr., Odessey R, Goldberg AL (1997). Inhibitors of the proteasome reduce the accelerated proteolysis in atrophying rat skeletal muscles. J Clin Invest 100 (1): 197203

90. Tews DS (2002). Apoptosis and muscle fibre loss in neuromuscular disorders. Neuromuscul Disord 12 (7-8): 613-622

91. Thomason DB, Booth FW (1990). Atrophy of the soleus muscle by hindlimb unweighting. J Appl Physiol 68 (1): 1-12

92. Vermeulen K, Berneman ZN, Van Bockstaele DR (2003). Cell cycle and apoptosis. Cell Prolif 36 (3): 165-175

93. Vescovo G, Ambrosio GB, Dalla Libera L (2001). Apoptosis and changes in contractile protein pattern in the skeletal muscle in heart failure. Acta Physiol Scand 171 (3): 305-310

94. Welle S (2002). Cellular and molecular basis of age-related sarcopenia. Can J Appl Physiol 27 (1): 19-41

95. West JB (2000). Physiology in microgravity. J Appl Physiol 89 (1): 379-384. 